\title{
Histone target selection within chromatin: an exemplary case of teamwork
}

\author{
Marie-Eve Lalonde, Xue Cheng, and Jacques Côté ${ }^{1}$ \\ St-Patrick Research Group in Basic Oncology, Laval University Cancer Research Center, Centre de Recherche du CHU de \\ Québec-Axe Oncologie, Hôtel-Dieu de Québec, Quebec City, Quebec G1R 2J6, Canada
}

\begin{abstract}
Histone modifiers like acetyltransferases, methyltransferases, and demethylases are critical regulators of most DNA-based nuclear processes, de facto controlling cell cycle progression and cell fate. These enzymes perform very precise post-translational modifications on specific histone residues, which in turn are recognized by different effector modules/proteins. We now have a better understanding of how these enzymes exhibit such specificity. As they often reside in multisubunit complexes, they use associated factors to target their substrates within chromatin structure and select specific histone mark-bearing nucleosomes. In this review, we cover the current understanding of how histone modifiers select their histone targets. We also explain how different experimental approaches can lead to conflicting results about the histone specificity and function of these enzymes.
\end{abstract}

Chromatin is a very dynamic structure, allowing compaction of DNA in the cell nuclei. The basic unit of chromatin is the nucleosome, which is composed of an octamer of the four canonical histones (H2A, H2B, H3, and H4), around which 147 base pairs (bp) of DNA is wrapped. Many actors regulate access to the DNA within chromatin, such as ATP-dependent remodeling complexes, histone chaperones, histone variants, and chromatin-modifying complexes. Post-translational modifications (PTMs) of histones mostly occur on their N-terminal tails. They play a major role in the regulation of the chromatin dynamic by either influencing its higher-order structural organization or recruiting different proteins implicated in diverse biological functions. Four major histone modifications have been shown to influence chromatin accessibility; namely, lysine acetylation, lysine/arginine methylation, serine/threonine phosphorylation, and lysine ubiquitination. More recently, new PTMs, including lysine acylation or crotonylation and serine glycosylation, have begun to emerge, but little is known about how they

[Keywords: acetyltransferases; methyltransferases; histone-modifying complexes; histone tails; chromatin readers]

${ }^{1}$ Corresponding author

E-mail jacques.cote@crhdq.ulaval.ca

Article is online at http://www.genesdev.org/cgi/doi/10.1101/gad.236331.113. influence chromatin dynamics (Tan et al. 2011; Zentner and Henikoff 2013).

Histone PTMs can be deposited on or removed from chromatin by different enzymes. These "writers" and "erasers" of histone marks include different kinases and phosphatases, ubiquitin ligases and deubiquitinases, lysine/arginine methyltransferases, and demethylases. To date, numerous lysine methyltransferases have been identified, and each can either mono-, di-, or trimethylate and may act on only a specific methylation status of a residue. Conversely, there are two classes of histone lysine demethylases identified: the LSD1 family (found only in humans/mammals) and the Jumonjis (Greer and Shi 2012).

Lysine acetylation entails the addition of an acetyl group on histone residues by histone acetyltransferases (HATs) and their removal by histone deacetylases (HDACs). HATs and HDACs were the first modifiers isolated, and since then, countless studies have extensively described their interactions with chromatin. Not only has characterization of HATs and HDACs been very useful to understand their recruitment to chromatin and their specific activity, but they have also served as a model of how other types of modifiers use similar features for their own binding and activity. There are two major classes of HATs: the GNAT (Gcn5 N-acetyltransferase) family and the MYST (Moz, Ybf2 [Sas3], Sas2, and Tip60) family. Other HATs with less clearly conserved catalytic domains also exist, the most recognized being $\mathrm{CBP} / \mathrm{p} 300$. Acetyl marks are removed by three major classes of HDACs, classified according to their homology with the yeast enzymes Rpd3, Hda1, and NAD-dependent Sir2/sirtuin (for review, see Steunou et al. 2014).

Histone PTMs can influence chromatin accessibility in two ways. Some modifications have direct impact on its structural organization by affecting nucleosome properties or higher-order chromatin structure. Other modifications can also act as docking sites for histone PTM "readers," which bind chromatin through their histone

(C) 2014 Lalonde et al. This article is distributed exclusively by Cold Spring Harbor Laboratory Press for the first six months after the full-issue publication date (see http://genesdev.cshlp.org/site/misc/terms.xhtml). After six months, it is available under a Creative Commons License (Attribution-NonCommercial 4.0 International), as described at http:// creativecommons.org/licenses/by-nc/4.0/. 
modification recognition domains (Musselman et al. 2012b). Some of these factors may also alter chromatin conformation, and the majority are involved in cellular functions such as DNA replication or repair, cell cycle progression, or transcriptional regulation. Therefore, PTMs play a major role in controlling various nuclear processes. A well-balanced homeostasis of the incorporation of these PTMs is thus required for the cells to maintain a tight regulation of cellular pathways. Not only does the deposition timing play a crucial role, but their genomic localization also needs to be highly specific. In fact, many diseases have been associated with the misincorporation of histone marks. Several other reviews have focused on the mechanisms of PTM misregulation leading to disease (Chi et al. 2010; Fullgrabe et al. 2011; Smith et al. 2011; Dawson and Kouzarides 2012; Shen and Laird 2013; Steunou et al. 2014).

Most of the chromatin-modifying enzymes have adopted a very ingenious strategy to guarantee such accurate deposition and specificity of histone PTMs. These catalytic proteins are generally found within large multisubunit complexes. Many subunits of these complexes contain different histone recognition modules that can bind chromatin on particular histone marks. Together, they cooperate to bind and target only specific residues on chromatin (Yun et al. 2011; Musselman et al. 2012b). Moreover, some of these complexes also possess more than one activity. For example, the SAGA complex has both acetyltransferase (Gcn5) and deubiquitinase (Ubp8) activities (Ingvarsdottir et al. 2005; Lee et al. 2005), while the related ATAC complex possesses two acetyltransferases (Gcn5 and Atac2) (Suganuma et al. 2008). Other complexes, such as TIP60, combine chromatin remodeling (H2A.Z incorporation by the $\mathrm{p} 400$ subunit) and modifying activities (acetylation by the Tip60 subunit) (Kusch et al. 2004; Altaf et al. 2009). These large complexes are thus multifunctional and can act in different cell processes by achieving various modifications depending on the cellular context. This review describes the major determinants that allow enzymes to modify histones in their specific physiological context, selecting, for example, specific nucleosomes and histone tail/ residues. As a great deal of data has accumulated in the past years concerning these multisubunit chromatinmodifying complexes, clarification is needed on some issues regarding factors required for substrate specificity and action on chromatin. We also shed light on some discrepancies related to these different complexes that can be found in the literature.

\section{The molecular context of substrates and enzymes influences the specificity of histone modifiers}

\section{Histone substrates}

Since chromatin is a dynamic structure, histones can be incorporated or evicted at various stages. Newly synthesized histones are normally incorporated during the $\mathrm{S}$ phase of the cell cycle, while eviction can occur during processes such as transcription, replication, and repair.
Therefore, a pool of free histones can be isolated in the nucleoplasm, although the majority is still bound to chromatin. Both conditions can also be recreated in vitro, where free histones and chromatin/nucleosomes may be used to characterize diverse modifying activities. Moreover, fewer physiological substrates like monomeric recombinant histone and histone $\mathrm{N}$-terminal synthetic peptides are also frequently used. These different substrates have allowed identification of context-specific activities (Fig. 1A,B). For instance, some enzymes react only with nucleosomal histones. The Dot 1 methyltransferase, which is responsible for the methylation of H3K79 in yeast, is able to accomplish this only in the context of chromatin and has no activity on free histones or recombinant H3 (Lacoste et al. 2002; Ng et al. 2002; Fingerman et al. 2007). The same is observed in the case of Set2 methyltransferase, which methylates H3K36 mainly in a chromatin context (Strahl et al. 2002), although minor relative Set2 activity has also been reported on histone tetramers and core histones (Du et al. 2008). In contrast, some other enzymes are able to acetylate only nonnucleosomal histones. The yeast acetyltransferase Rtt109, which is found in complex with the histone chaperone Vps75, acetylates H3K56 of newly synthesized histones in the nucleoplasm but does not acetylate nucleosomal H3 (Han et al. 2007). The Asf1 chaperone is also required for Rtt109 to acetylate H3K56 by presenting H3H4-associated dimers to the enzyme (Recht et al. 2006; Adkins et al. 2007). Other enzymes can modify both free histones and nucleosomes but show clear preferences in vitro, as shown by $\mathrm{CBP} / \mathrm{p} 300$ acetyltransferase' s stronger activity on free histones compared with chromatin (Ogryzko et al. 1998; Ito et al. 2000; Deng et al. 2003). Interestingly, some HAT complexes can target both free and nucleosomal histones in vitro but will show differential specificity for each substrate. The MYST complex HBO1-JADE can acetylate both $\mathrm{H} 3$ and $\mathrm{H} 4$ on free histones but is much more specific for $\mathrm{H} 4$ in the context of nucleosomes (Doyon et al. 2006; Saksouk et al. 2009; Lalonde et al. 2013). The same is true for the MOZ/ MORF-BRPF MYST complex and the equivalent yeast NuA3 complex, in which both H3 and H4 can be acetylated on free histones, but only $\mathrm{H} 3$ gets acetylated on nucleosomes (John et al. 2000; Ullah et al. 2008; Lalonde et al. 2013). In addition, acetylation of a specific histone tail may be detected only in the context of chromatin. This is the case for human TIP60 and homologous yeast NuA4 complexes, which are specific for acetylation of $\mathrm{H} 2 \mathrm{~A}$ and $\mathrm{H} 4$ when using chromatin as substrate, while very low levels of acetylated H2A are detected with free histones (Allard et al. 1999; Doyon et al. 2006). Similarly, Gcn5containing HAT complexes target the H2B tail only in a chromatin context (Grant et al. 1997, 1999; Allard et al. 1999). Overall, while most nuclear histone modifiers are less active on nucleosomal substrates as compared with free histones, their real histone specificity is better revealed when using their physiological substrate. This extends even to the histone proteins themselves, as sequence variations between species can affect apparent specificity when using modifiers from heterologous sys- 

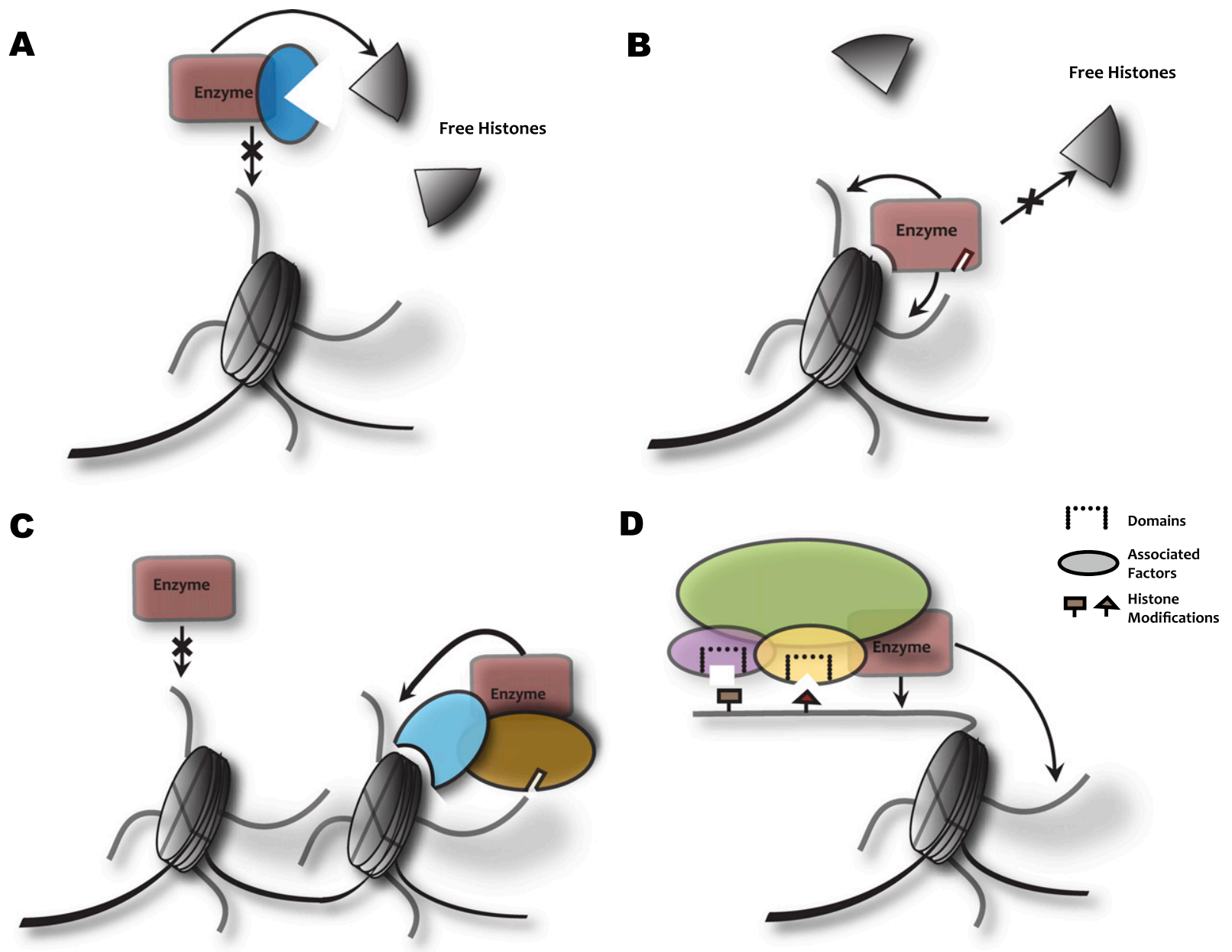

Figure 1. Mechanisms of substrate selectivity endowed by chromatin-modifying enzymes themselves or their associated factors. $(A)$ Binding of associated factors enables enzymes to act on free histones but not on nucleosomes. (B) Specific structure/motifs/domains within the enzyme itself ensure its activity on nucleosomes rather than on free histones. $(C)$ Accommodation in the multisubunit complexes enables enzyme activities on nucleosome substrates. $(D)$ Various recognition/reader domains within associated factors guide enzymatic activity to specific histone modification chromatin landscape.

tems. This is largely seen with the less conserved H2A/ H2A.Z and H2B N-terminal tails (e.g., Allard et al. 1999; Altaf et al. 2010).

\section{Histone modifier enzymes}

Another aspect that influences specificity of histone modifiers is the molecular context in which they reside when used in assays. This context specificity is demonstrated when recombinant enzymes show differential activity when compared with their native complexes. Since most of the chromatin-modifying enzymes are normally contained in multisubunit complexes, their associated factors may help potentiate their nucleosomal activity and may also change their specificity of action (Fig. 1C). The Gen5 HAT is found within different complexes in vivo; namely, ADA/HAT-A2, SAGA, SLIK, and ATAC (Steunou et al. 2014). Recombinant yGcn5 enzyme mainly acetylates $\mathrm{H} 3$ and, to a lesser extent, $\mathrm{H} 4$ in free histones but is unable to target nucleosomes (Kuo et al.
1996; Grant et al. 1997). Its specificity toward free histones is not drastically changed within native complexes, but it is now able to modify chromatin substrates with a specificity corresponding to its in vivo action toward H3 and H2B (Grant et al. 1999; Suka et al. 2001). Esal/ Tip60(KAT5) acetylation activity also shows distinctive results when comparing both the recombinant proteins and the native complexes. It always acetylates $\mathrm{H} 4$ and $\mathrm{H} 3$ and weakly acetylates $\mathrm{H} 2 \mathrm{~A}$ on free histones, whereas only the native complexes (NuA4/TIP60-p400) can target chromatin, modifying $\mathrm{H} 4$ and $\mathrm{H} 2 \mathrm{~A}$ as reported in vivo (Allard et al. 1999; Suka et al. 2001; Doyon et al. 2006). Thus, in several cases, native complexes enable the enzymes to modify chromatin substrates. In most other cases, it can also potentiate their activity toward their physiological substrates, greatly increasing their specific activity. Many methyltransferases are also active as recombinant proteins toward free histones but require associated factors in native complexes to efficiently target chromatin. Such is the case for MLL/Set1 and EZH2, which use associated 
subunits to enable their activity on nucleosomes (Shilatifard 2012; Herz et al. 2013). In these examples, the recombinant enzymes show little to no activity on free histones. Human EZH2 needs to reside in the Polycomb-repressive complex 2 (PRC2) complex in order to methylate H3K27 on both chromatin and free histones (Margueron and Reinberg 2011). Thus, associated factors found within these multisubunit chromatin-modifying complexes are often key players for the enzymes to have substantial and specific activity on chromatin. Furthermore, as for the substrate context, the use of native modifier complexes more closely recapitulates the in vitro histone specificity that corresponds to in vivo targets.

\section{Associated factors enable enzymes to modify histones in the context of chromatin}

Evidence shows that the distinct behavior of recombinant enzymes and their native complexes makes sense when considering the fact that this incorporation actually endows the enzymes with the ability and specificity to act on chromatin. Kinetic differences shown in studies comparing individual HAT subunits with their respective physiological complexes further highlighted the important chromatin-binding property that associated factors lent to the enzymes. For example, incorporation of Esal into the core complex Piccolo NuA4 enhances its catalytic efficiency on nucleosome substrates by 3500 -fold compared with Esal alone (Berndsen et al. 2007), making it strikingly more active on chromatin than on free histones (Boudreault et al. 2003). This significant difference can be explained by the presence of the Piccolo NuA4-associated factors Yng2 and Epl1 (Boudreault et al. 2003; Selleck et al. 2005; Chittuluru et al. 2011; Huang and Tan 2013). Similarly, the presence of Ada2 and Ada3 is required for Gen5-containing complexes to act on chromatin (Sendra et al. 2000; Balasubramanian et al. 2002; Carrozza et al. 2003). Yng2 is part of the inhibitor of growth (ING) family of tumor suppressors, which are primarily found as subunits of conserved HAT or HDAC complexes in eukaryotes (Doyon et al. 2006). These factors are required for efficient modification of chromatin by NuA4, NuA3, Tip60, HBO1, MOZ/MORF, and Rpd3L in vitro and in vivo (Saksouk et al. 2008; Ullah et al. 2008). Notably, the chromatin acetylation property provided by ING proteins lies outside of their PHD (plant homeodomain) (Boudreault et al. 2003; Doyon et al. 2004; Selleck et al. 2005; Chruscicki et al. 2010), a module associated with the binding of methylated histones (Musselman et al. 2012b). Interaction of the MSL1 and MSL3 subunits with the MOF catalytic subunit leads to its H4K16-specific HAT activity on chromatin in vitro and in vivo (Morales et al. 2004; Smith et al. 2005). As for the MLL1/Set1 methyltransferases, it has been reported that a fully assembled MLL1 core complex containing a stoichiometric equivalent of the catalytic subunit MLL1 and associated subunits WRAD (WDR5, RbBP5, ASH2L, and DPY-30) is required for nucleosomal H3K4 methylation (Patel et al. 2011), although the specific mechanism appears intricate (Shilatifard 2012; Couture and Skiniotis 2013). In parallel, methyltransferase EZH2, residing in the PRC2 complex, requires the SUZ12 and RbAp46/48 subunits to bind nucleosomes and Eed to stimulate methylation of nucleosomal H3K27 (Margueron and Reinberg 2011).

Interestingly, results from multiple studies indicate that specific protein domains present in these associated factors also contribute to chromatin binding, enabling activity toward nucleosomal histones. For example, while PHD fingers and chromodomains are mostly thought of as reader modules for histone methyl marks, a number of them are essential for modification of histones in the context of chromatin regardless of methylation. For instance, PZP (PHD-Zn knuckle-PHD) domains are present in the scaffold proteins BRPF/JADE of HBOl and MOZ/MORF HAT complexes. This domain acts as a single functional entity and is essential for chromatin binding and acetylation by these complexes both in vivo and in vitro (Foy et al. 2008; Saksouk et al. 2009; Avvakumov et al. 2012; Lalonde et al. 2013). The binding mechanism appears to occur through coordinated association of the PZP with histone $\mathrm{H} 3 \mathrm{~N}$-terminal tails and nucleosomal DNA (Saksouk et al. 2009; Liu et al. 2012; Lalonde et al. 2013). Moreover, the Esal chromodomain, while not required for activity on free histones, is essential for acetylation of chromatin substrates by piccolo NuA4 (Selleck et al. 2005; Huang and Tan 2013). Although this domain is proposed to recognize methyl marks in the homologous human enzyme (Tip60) (Sun et al. 2009; Jeong et al. 2011), its mutation cripples the activity of the yeast complex on recombinant nucleosomes lacking any PTMs and is lethal. This again supports the idea that the domain recognizes a histone-DNA interface in the nucleosome particle, which is corroborated by biochemical/structural data (Huang and Tan 2013). Similarities can be drawn to Drosophila MOF, also part of the MYST HAT family, which has a chromobarrel domain required for the acetylation of H4K16. This domain not only directly binds to nucleic acids but also potentiates MOF's enzymatic activity after chromatin binding (Conrad et al. 2012). Another example is the PHD present in the Rcol subunit of the Rpd3S HDAC complex. It enhances the overall affinity of Rpd3S for nucleosomes, cooperating with the chromodomain of Eaf3 that provides specificity for H3K36 methylated nucleosomes, a marker of genes transcribed by RNA polymerase II (RNAPII) (Li et al. 2007). These examples highlight different mechanisms that these modifying enzymes have adopted to selectively act on histones within the context of chromatin.

\section{Selection of specific PTM-carrying nucleosomes by modifier enzymes or their associated factors}

Many of the associated factors found within the chromatin-modifying complexes can act as readers of histone PTMs via their different chromatin recognition domains. By recognizing various histone marks, these domains promote the binding of regulatory complexes to distinct loci and, in some cases, orient them to target a specific histone tail (Fig. 1D). For example, methylation can be read by many domains such as PHD, CHD, and Tudor, 
while acetylation markers mainly recruit bromodomaincontaining proteins. Musselman et al. (2012b) provide a detailed review on the different types of chromatin recognition domains and their modes of binding. Subunits of MYST acetyltransferase complexes contain many of these recognition modules. First, they possess an ING protein (or Yng in yeast) that has a PHD with high affinity for H3K4me3 (Martin et al. 2006; Shi et al. 2006; Champagne et al. 2008; Hung et al. 2009; Saksouk et al. 2009). The presence of this domain is linked to the binding of these different modifying complexes near the transcription start site of active genes, where H3K4me2/3 is concentrated (Saksouk et al. 2009; Avvakumov et al. 2012; Lalonde et al. 2013). This interaction can potentiate acetylation of the histone $\mathrm{H} 3$ tail. Indeed, the presence of the ING4/5 (or yeast Yng1) subunit in complexes stimulates H3K14 acetylation when H3K4 is di-/trimethylated (Taverna et al. 2006; Hung et al. 2009; Saksouk et al. 2009; Avvakumov et al. 2012; Lalonde et al. 2013). Interestingly, it does so even in the HBO1-JADE1 complex, which generally targets the $\mathrm{H} 4$ tail on nucleosomes, slightly changing its histone tail specificity (Saksouk et al. 2009). Therefore, ING proteins have two distinct modules that function in driving chromatin (de)acetylation by different native complexes. As mentioned above, besides the PHD$\mathrm{H} 3 \mathrm{~K} 4 \mathrm{me} 2 / 3$ interaction, they also contain an $\mathrm{N}$-terminal region that potentiates activity on chromatin substrates (not on free histones) (Boudreault et al. 2003; Selleck et al. 2005; Doyon et al. 2006; Chruscicki et al. 2010). On the other hand, this $\mathrm{N}$-terminal chromatin-binding function of ING proteins appears less important in complexes like $\mathrm{HBO} 1$ and MOZ/MORF that contain a potent chromatin- binding PZP domain (in JADE/BRPF scaffold subunits) (Saksouk et al. 2009; Avvakumov et al. 2012). In these cases, the mechanism of binding and modification of chromatin becomes a complicated cross-talk between protein domains and histone tails (Fig. 2A). In fact, the PZP domain allows binding to nucleosomes in part through an interaction with the $\mathrm{H} 3$ tail. This interaction is very sensitive to the methylation status of $\mathrm{H} 3 \mathrm{~K} 4$, as it is disrupted even by monomethylation (Saksouk et al. 2009; Qin et al. 2011; Lalonde et al. 2013). Interestingly, the regulated presence of the ING subunit with its PHD reverses this sensitivity to H3K4me (Saksouk et al. 2009; Avvakumov et al. 2012; Lalonde et al. 2013). In addition to the PZP domain, the BRPF scaffold subunit of the HBO1 and MOZ/MORF HAT complexes contains a PWWP domain that binds $\mathrm{H} 3 \mathrm{~K} 36 \mathrm{me} 3$ and regulates binding to chromatin in vivo (Fig. 2A; Laue et al. 2008; Vezzoli et al. 2010). Furthermore, BRPF proteins also contain a bromodomain with good affinity for Kac, but the physiological target and function of this domain remain to be elucidated (Filippakopoulos et al. 2012; Lalonde et al. 2013).

The MSL3 subunit of the MOF HAT complex is linked to X-chromosome dosage compensation mechanisms. It possesses a chromodomain that promotes acetylation of H4K16 by allowing spreading on H3K36me3-containing chromosomal regions (Larschan et al. 2007; Sural et al. 2008). The Eaf3 subunit (MRG15 in humans) of the Rpd3S deacetylase complexes has a related chromobarrel domain that also binds $\mathrm{H} 3 \mathrm{~K} 36 \mathrm{me} 2 / 3$. While this interaction is not important for recruitment of the complexes to the body of active genes, it is required for histone deacetylation to occur behind the elongating polymerase to stabi-

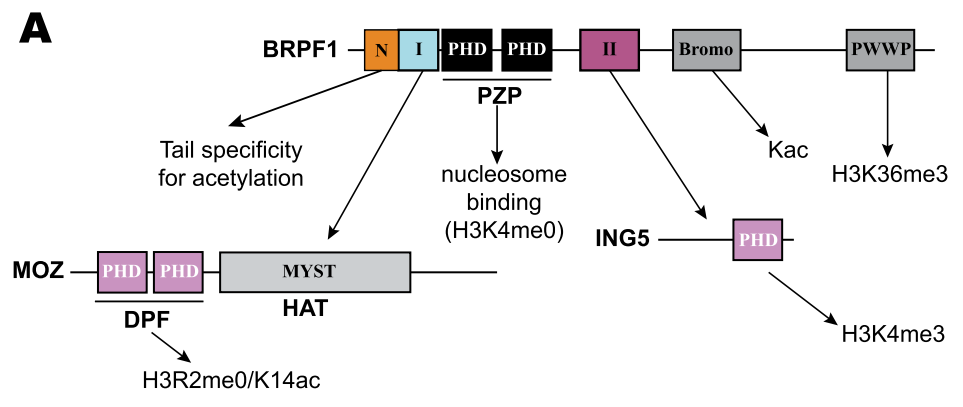

B

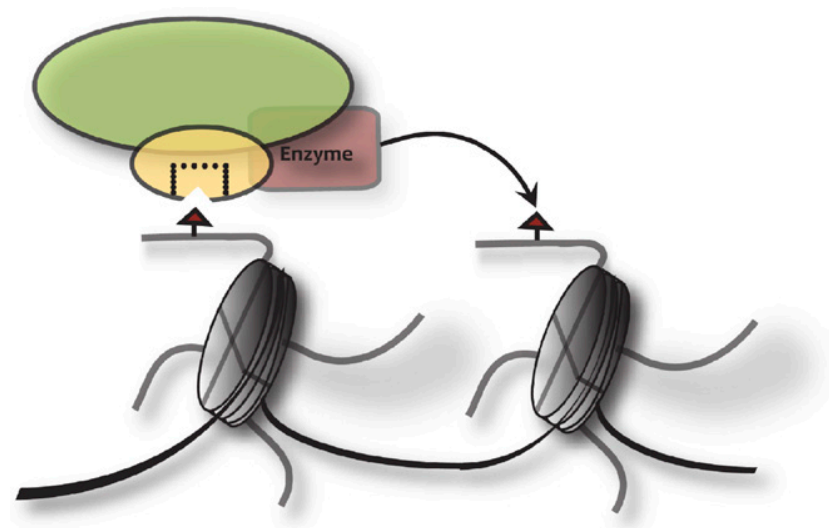

Figure 2. Multiplicity and multivalence of histone reader and chromatin-binding modules within histone modifier complexes, reflecting multifunctional epigenetic effectors. (A) The case of the MOZ HAT complex. The native tetrameric MOZ histone H3-specific acetyltransferase complex is depicted with its known domains of interaction between subunits, with specific histone marks, and with nucleosomes. (DPF) Double PHD fingers. For simplicity, the small uncharacterized hEaf6 subunit is not presented. (B) Local propagation of a histone mark by chromatin modifiers. This is achieved through an associated reader module that recognizes the same mark that is deposited by the enzyme, allowing modification of the second histone tail within the nucleosome and/or the tails on the neighboring nucleosomes. This mechanism is thought to be critical for epigenetic inheritance during replication/cell division. 
lize nucleosomes and avoid spurious transcription (for review, see Smolle et al. 2013). This Eaf3/MRG15 protein is also part of the NuA4/TIP60 acetyltransferase complex, but its role in less understood, although it is again likely linked to transcription elongation. As mentioned above, modifying enzymes themselves can also contain histone mark reader modules. The MOZ/MORF HATs have tandem PHDs that favor interaction with H3K14ac and unmodified H3R2 (Ali et al. 2012; Qiu et al. 2012). Tip60 has a chromodomain that can interact with H3K4mel at the transcription enhancer elements (Jeong et al. 2011). Clearly, MYST family acetyltransferase complexes contain many histone PTM recognition domains (e.g., Fig. 2A). Further study will be required in order to fully understand how these different modules cooperate to target very specific loci.

Besides MYST family HAT complexes, other multisubunit histone-modifying complexes also harbor many PTM recognition modules. The Gcn5-containing SAGA complex includes the Sgf29 subunit with its tandem Tudor domains. This module binds to $\mathrm{H} 3 \mathrm{~K} 4 \mathrm{me} 2 / 3$ and is required for $\mathrm{H} 3$ acetylation by the complex in vivo (Vermeulen et al. 2010; Bian et al. 2011). The PRC2 is responsible for the deposition of $\mathrm{H} 3 \mathrm{~K} 27 \mathrm{me} 3$ at silenced genes. Its catalytic activity resides within the EZH2 subunit but also depends on at least three other subunits in human cells: SUZ12, Eed (equivalent to the Drosophila ESC), and RbAp46/48 (Margueron and Reinberg 2011). The C-terminal of Eed contains a WD40 domain that can bind to $\mathrm{H} 3 \mathrm{~K} 27 \mathrm{me} 3$ and ensures the propagation of the repressive mark on chromatin by allowing the allosteric activation of the methyltransferase activity of the complex (Margueron et al. 2009). Moreover, in flies, the $\mathrm{N}$ terminus of the ESC protein has been shown to bind directly to histone $\mathrm{H} 3$ and promote $\mathrm{H} 3 \mathrm{~K} 27 \mathrm{me} 3$ (Tie et al. 2007). In addition, one of the alternative complex subunits, PHF1/ $\mathrm{Pcl}$, can also modulate the PRC2 complex activity (Cao et al. 2008; Sarma et al. 2008). Its N-terminal Tudor domain can recognize H3K36me3-containing chromatin, either inhibiting Ezh2 from methylating H3K27 or promoting its spreading and silencing on embryonic stem cell genes (Abed and Jones 2012; Musselman et al. 2012a; Cai et al. 2013). The Set1 methyltransferase is a member of the COMPASS complex (MLL1/Setla/Set1b complexes in humans). Local propagation of a histone mark is frequently achieved through a subunit/reader module associated with the enzyme that recognizes the deposited PTM (Fig. 2B). As for Eed in PRC2, the H3K4me2/3-binding PHD of the COMPASS subunit Spp1 favors deposition of the same histone mark that it recognizes (Acquaviva et al. 2013). This is likely also the case for the LSD1 H3K4 demethylase complex, as its PHD-containing BHC80 subunit binds to unmethylated $\mathrm{H} 3 \mathrm{~K} 4$ and is required for the repressive transcriptional activity of the complex (Lan et al. 2007).

Furthermore, PSIP1/LEDGF/p75, another important factor that associates with the MLL HMT complex, has a newly characterized PWWP domain that binds both DNA and H3K36me3 (van Nuland et al. 2013). Again, some histone PTM-binding modules can also be found within the enzymes themselves. The MLL1 methyltrans- ferase has four PHDs, where the third can bind to H3K4me3 (Chang et al. 2010; Wang et al. 2010). The third PHD of MLL2 and the single PHD of MLL5 also both recognize this same histone mark (Ali et al. 2013, 2014; Lemak et al. 2013). This is likely related to Spp1 function in homologous yeast COMPASS (see above) for efficient propagation of this critical histone mark. In contrast, the MLL4 triple PHD finger cassette associates with unmodified histone $\mathrm{H} 4$ or asymmetrically dimethylated H4R3me2 (Dhar et al. 2012). Similarly, the Jhd2 H3K4 demethylase possesses a PHD required for the enzyme to bind nucleosomes, but its binding function is independent of the H3 tail (Huang et al. 2010). Finally, another clear example of cross-talk between a reader module and catalysis within a modifying enzyme is PHF8, a H3K9 demethylase that contains a PHD specific for H3K4me3 and required for the catalytic activity of the protein (Feng et al. 2010; Fortschegger et al. 2010; Horton et al. 2010). In this case, these antagonistic histone marks can be efficiently kept away from each other.

\section{Selection of the specific histone tail to be modified by enzymes on nucleosomes: new intriguing mechanisms}

While associated factors/domains in native complexes can enable the activity of modifying enzymes on chromatin substrates and direct them to specific PTM-carrying nucleosomes, it was generally thought that the selection of the histone tail and residue to be modified was mostly performed by the enzyme itself. Domains have been mapped in modifying enzymes that bind one specific histone tail or region within a nucleosome in order to target another. For example, the N-terminal region of the Set2 methyltransferase interacts with the $\mathrm{H} 4$ tail within the nucleosome in order to target $\mathrm{K} 36$ of $\mathrm{H} 3$ for methylation (Du et al. 2008). Similarly, Dot1 methyltransferase contains an acidic patch in the C-terminal that can bind to a basic patch contained in the $\mathrm{N}$-terminal tail of $\mathrm{H} 4$, and this interaction is required for $\mathrm{H} 3 \mathrm{~K} 79$ methylation (Altaf et al. 2007; Fingerman et al. 2007).

As mentioned above, some reader subunits like ING proteins in $\mathrm{HBO} 1$ complexes can slightly change specificity by increasing activity toward $\mathrm{H} 3$ without affecting acetylation of the main H4 target (Saksouk et al. 2009). However, recent work has shed light on a new mechanism by which some subunits in native modifying complexes can strictly select which specific histone tail gets targeted by the catalytic subunit. We and others have recently discovered that the HBO1 HAT enzyme exists in different native complexes with JADE or BRPF paralogs as scaffold subunit (Doyon et al. 2006; Mishima et al. 2011; Lalonde et al. 2013). While the HBO1-JADE and HBO1-BRPF complexes acetylate $\mathrm{H} 3$ and $\mathrm{H} 4$ equally on free histones, they are exclusively specific for H4 (JADE) or H3 (BRPF) on chromatin (Lalonde et al. 2013). Thus, the HBOlassociated scaffold subunit directs which histone tail gets acetylated by the enzyme on chromatin. In fact, a small region at the $\mathrm{N}$ terminus of both the JADE and BRPF proteins is responsible for selecting the $\mathrm{H} 3$ or $\mathrm{H} 4$ tail for acetylation. This is a conceptually novel regulatory mech- 
anism in which the histone tail specificity of an enzyme is determined by the native complex it resides in and in which an exchange of subunits leads to a completely distinct acetylation specificity (Fig. 3B). This has clear implications on conclusions that can be drawn from experiments using modifying enzymes outside of their physiological environment (e.g., transient overexpression without associated factors). The small region mapped on JADE and BRPF proteins is related to a similar N-terminal region of the EPC1/Epll scaffold subunits of the TIP60 (humans) and NuA4 (yeast) H4/H2A-specific HAT complexes. It previously had been shown to be important for binding to nucleosomes and for acetylation and was found to interact with the histone $\mathrm{H} 2 \mathrm{~A} \mathrm{~N}$-terminal tail within the nucleosome (Selleck et al. 2005; Chittuluru et al. 2011; Huang and Tan 2013). Further analysis demonstrated that this domain was essential for Tip60/NuA4 to acetylate the nucleosomal $\mathrm{H} 4$ tail, while acetylation of the nucleosomal H2A tail was still detected (Lalonde et al. 2013). Thus, this small basic region of EPC1/Epl1, through its interaction with the H2A tail, appears to orient the Tip60/NuA4 complex in a specific manner on the nucleosome so that the catalytic subunit can acetylate the $\mathrm{H} 4$ tail. The fact that acetylation of $\mathrm{H} 2 \mathrm{~A}$ is still possible implies that different mechanisms of nucleosome binding are at play to acetylate the two tails.

\section{Conflicting reports on specificity of histone modifiers: Where is the truth?}

The fact that the apparent in vitro specificity of histone modifiers is affected by several factors may explain the presence of many discrepancies in the literature related to

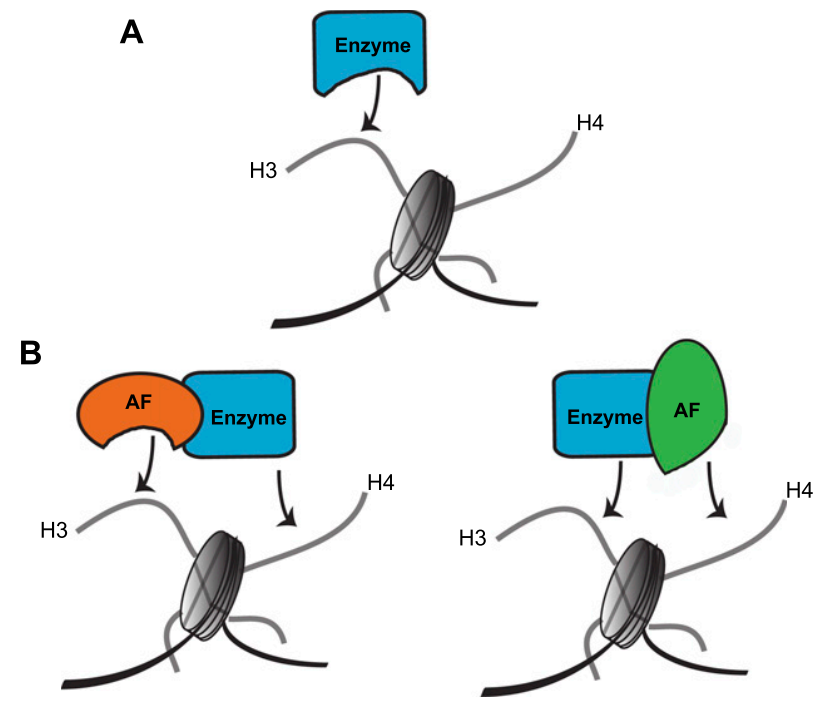

Figure 3. Selection of histone tail specificity of chromatin modifiers resides in the enzymes themselves or can be decided by domains within associated factors. $(A)$ Domains within the enzymes themselves select a specific histone tail for modification. (B) Exchangeable associated factors (AFs) can associate with the same enzyme and bind distinct histone domains within the nucleosome, leading to different histone tails being selected for modification. their real targets. As discussed above, the molecular context of the substrate itself influences the apparent specificity of modifiers (free histones or N-terminal peptides vs. chromatin). The use of recombinant or overexpressed enzymes compared with protein complexes also generates a great deal of variation in reported specificity. Overall, the use of native purified activities or reconstituted complexes with their physiological substrates like nucleosomes is by far the best way to recapitulate the real in vivo specific targets of histone modifiers. It is now clear that associated factors within chromatin-modifying complexes are crucial in allowing enzymes to modify nucleosomal histones, select specific PTM-carrying nucleosomes, and, in some cases, choose which histone tail/ residue is targeted. Therefore, apparent discrepancies have accumulated in the literature about the specificity of several modifiers, since many experiments were performed using, for example, histone peptides as substrate and/or only the enzymatic subunits outside of their natural multisubunit complexes. In fact, transient overexpression of monomeric enzymes or even of other complex subunits often creates a distinct phenotype. For example, the MYST HAT scaffold subunit BRPF1 is mainly localized in the cytoplasm when individually overexpressed (Ullah et al. 2008). However, when cotransfected with its enzymatic partner, MOZ, its localization turns out to be mainly nuclear. Interestingly, the localization of the MOZ protein itself within chromatin varies when overexpressed individually. In this condition, it dislikes H3K4me3 chromatin but colocalizes with H3K14ac marks, as shown by immunofluorescence experiments (Qiu et al. 2012; Dreveny et al. 2014). In contrast, since native MOZ is found in a complex with BRPF and ING subunits (Fig. 2A), its genome-wide localization correlates with H3K4me3enriched chromatin regions through the PHD of ING5 (Champagne et al. 2008; Lalonde et al. 2013). The caveat here is to take into account the limitations in interpreting results from individual studies based on the different materials used and methods adopted.

Besides the discrepancy resulting from different experimental strategies, the potential tissue-specific activities could also contribute to the seemingly divergent results. For example, complete depletion of the MOZ acetyltransferase in mouse embryos decreases the acetylation of H3K9 at specific genomic loci, although the MOZ complex has been shown to acetylate H3K14 in chromatin (Doyon et al. 2006; Ullah et al. 2008; Voss et al. 2009; Lalonde et al. 2013). Furthermore, while depletion of the HBO1 acetyltransferase by siRNAs in HeLa or H1299 cells leads to a significant decrease of $\mathrm{H} 4$ acetylation (K5, $\mathrm{K} 8$, and K12) and appears to have an impact on cell cycle progression into S phase (Doyon et al. 2006; Miotto and Struhl 2010; Havasi et al. 2013), its complete knockout in mouse embryos shows only a loss of H3K14ac in mouse embryonic fibroblasts with no apparent replicative defect (Kueh et al. 2011). These differential phenotypes indicate that chromatin modifiers can also have tissue-specific activities and that the expression level of associated factors in different tissues or cell lines may influence their function. In fact, as mentioned above, HBO1 can associate 
with either the JADE or BRPF scaffold proteins, and this association is responsible for changing the enzyme's histone tail specificity (Lalonde et al. 2013). Although the BAF complexes act as chromatin remodelers and do not directly modify any histone residue, they have also been well documented for their tissue-specific variability (Hargreaves and Crabtree 2011). Indeed, during differentiation of embryonic stem cells into neuronal progenitors, BAF complexes undergo a complete subunit rearrangement in which BAF45a and BAF53a are replaced by the BAF45b and BAF53b subunits (Lessard et al. 2007). Moreover, the BAF60c subunit is only required for heart development in embryonic cells (Lickert et al. 2004). This supports the notion that chromatin-modifying complexes also undergo complex reorganization in which associated paralog subunits are selected through differentiation of the cells or are simply differentially expressed in various tissues. Such a mechanism provides a likely explanation for a number of the divergences observed in the literature.

Numerous PTMs exist on the various histone tails, making it logistically difficult to develop highly specific antibodies that both recognize a precise mark on a specific residue and have epitopes that are not altered by neighboring marks. It is no small point that one of the keys to the recent advances in the chromatin field has been the use of such antibodies. Unfortunately, one often sees antibodies with epitopes designed to recognize a specific acetylation or methylation mark that will also cross-react with another acetylated or methylated lysine residue. The use of such deficient tools clearly gives rise to inaccuracies that are often overlooked. Egelhofer et al. (2011) have estimated that about one out of four available commercial antibodies against histone modifications do not pass the specificity test by Western blot analysis. Moreover, many antibodies $(22 \%)$ do not generate reproducible data for chromatin immunoprecipitation (ChIP) experiments (Egelhofer et al. 2011). On the other hand, binding of antibodies against a precise histone modification is often inhibited by the presence of a nearby secondary histone mark, which blocks the recognition of the antibody epitope (Bock et al. 2011; Fuchs et al. 2011). Many of the observed in vivo phenotypes following depletion of chromatin modifiers rely on the specificity and sensitivity of these antibodies. To address any potential misinterpretations brought about by using these antibodies, quantitative mass spectrometry of histone modifications offers a more direct method to assess clear in vivo phenotypes. Additionally, while specific histone residues in yeast can be mutated to test for loss of signal, true controls for modification recognition in mammalian cells are lacking. Along with the aforementioned case of $\mathrm{HBO}$ and $\mathrm{MOZ}$ depletion, variable results have also been observed after depletion of different ATAC subunits. Whereas depletion of the Atac2 HAT subunit in both mice and humans creates a loss of H3K9, H4K5, H4K12, and H4K16 acetylation (Guelman et al. 2009), only H4K16ac is lost in flies (Suganuma et al. 2008). Also, depletion of the Ada2 subunit leads to a decrease of H3K9ac and H3K14ac in HeLa cells (Nagy et al. 2010), while its mutation in flies creates a drop in H4K12ac (Ciurciu et al. 2008). Discrepancies have also been observed for the Ash1L methyltransferase (homolog of Drosophila Ash1). Depletion of this protein by shRNA in 293T cells creates a loss of H3K4me3 in vivo (Gregory et al. 2007), while depletion in mouse embryonic stem cells mostly shows a loss of H3K36me3 (Miyazaki et al. 2013). These observed contradictions might be the result of poor antibody detection/specificity or varied roles of these enzymes in different tissues. On the other hand, in vivo depletion/overexpression of modifiers can easily produce indirect effects on other histone modifications not deposited by the enzymes. These indirect effects can be seen clearly on bulk chromatin but most often during ChIP analysis. They can occur due to global changes in chromatin dynamics, well-established cross-talk between histone marks, transcription activity, and/or cell cycle progression and can vary between cell lines and different loci. Since several histone marks are regulated during the cell cycle, any slight changes due to overexpression or knockdown of factors can mislead the investigator into linking a chromatin modification to a specific enzyme. In light of these possibilities, extra care should be taken when characterizing chromatin modifiers. Thus, the best experimental approach remains a combination of in vivo and in vitro studies in which targeted histone residues are validated in the test tube as well as in the cell. In addition, the use of native purified activities and physiological substrates in biochemical assays is the most credible approach to characterize the true specificity of histone modifiers.

\section{Regulation of modifiers by noncoding RNA and selection of nonhistone substrates by associated factors}

Recent years of studies have also witnessed the emerging functional interaction between noncoding RNAs and histone-modifying complexes through their associated factors. These interactions play important roles in the demarcation of chromatin domains, establishment of specific regional chromatin structures, and regulation of gene expression (Bonasio et al. 2010; Smolle et al. 2013; Hiragami-Hamada and Fischle 2014) and further highlight the importance of associated factor-mediated processes in the targeting of histone modifiers.

As we come to know more about the different chromatin-modifying complexes, their associated factors, and their specificity, reports of a number of nonhistone substrates targeted by these modifiers are emerging in the literature. Associated factors present within these complexes may also contribute to the acetylation specificity of these nonhistone substrates. A few targets have been identified for the MYST acetyltransferase family (for a detailed review, see (Sapountzi and Cote 2011), including the p53 tumor suppressor protein, which can be acetylated on different lysine residues by these enzymes (Sykes et al. 2006; Tang et al. 2006, 2008; Li et al. 2009; Rokudai et al. 2009, 2013). The MOF MYST acetyltransferase has been shown to be part of two separate complexes, MOFMSL and MOF-MSL1v1 (Smith et al. 2005; Li et al. 2009). Both complexes comprise two entirely different sets of subunits, and only the second can target p53 acetylation 
on K120, a mark favoring the apoptosis program instead of simple cell cycle arrest (Li et al. 2009).

\section{Conclusion}

Besides appreciating the intriguing mechanisms and the outstanding "teamwork spirit" that chromatin-modifying complexes have adopted for their precise and specific activity, scientists are also witnessing the mounting complexity of chromatin modulation produced by recent years of studies. With the help of their associated factors, chromatin-modifying enzymes are targeted to nucleosomes via distinct recognition/binding domains that also participate in specific histone tail selection. Regulation of the deposition of these PTMs not only influences the structural organization of chromatin but also controls a variety of cellular pathways. Indeed, misregulation of PTM deposition may contribute to the onset of tumorigenesis. It is therefore not surprising to find anti-cancer agents targeting histone modifiers and PTM reader modules (Rodriguez-Paredes and Esteller 2011; Dawson and Kouzarides 2012). Nevertheless, challenges remain, as the detailed picture of chromatin regulation by modifying complexes has not been fully unveiled, which particularly calls for complete and rigorous design of experiments and strict and critical interpretations of the data in the chromatin/epigenetic research field.

\section{Acknowledgments}

We apologize to our colleagues whose work could not be referenced due to space limitations. We thank Jean-François Couture, Rhea Utley, reviewers, and the editors for comments, suggestions, and text corrections. Work in our laboratory was supported by grants from the Canadian Institutes of Health Research (CIHR; MOP-14308 and MOP-64289|. M.-E.L. and X.C. acknowledge a FRQ-S studentship and a Fonds Wilbrod-Bhérer/Joseph-Demers award, respectively. J.C. holds a Canada Research Chair in Chromatin Biology and Molecular Epigenetics.

\section{References}

Abed JA, Jones RS. 2012. H3K36me3 key to Polycomb-mediated gene silencing in lineage specification. Nat Struct Mol Biol 19: $1214-1215$.

Acquaviva L, Drogat J, Dehe PM, de la Roche Saint-Andre C, Geli V. 2013. Spp1 at the crossroads of H3K4me3 regulation and meiotic recombination. Epigenetics 8: 355-360.

Adkins MW, Carson JJ, English CM, Ramey CJ, Tyler JK. 2007. The histone chaperone anti-silencing function 1 stimulates the acetylation of newly synthesized histone $\mathrm{H} 3$ in S-phase. I Biol Chem 282: 1334-1340.

Ali M, Yan K, Lalonde ME, Degerny C, Rothbart SB, Strahl BD, Cote J, Yang XJ, Kutateladze TG. 2012. Tandem PHD fingers of MORF/MOZ acetyltransferases display selectivity for acetylated histone $\mathrm{H} 3$ and are required for the association with chromatin. J Mol Biol 424: 328-338.

Ali M, Rincon-Arano H, Zhao W, Rothbart SB, Tong Q, Parkhurst SM, Strahl BD, Deng LW, Groudine M, Kutateladze TG. 2013. Molecular basis for chromatin binding and regulation of MLL5. Proc Natl Acad Sci 110: 11296-11301.

Ali M, Hom RA, Blakeslee W, Ikenouye L, Kutateladze TG. 2014. Diverse functions of PHD fingers of the MLL/KMT2 subfamily. Biochim Biophys Acta 1843: 366-371.
Allard S, Utley RT, Savard J, Clarke A, Grant P, Brandl CJ, Pillus L, Workman JL, Cote J. 1999. NuA4, an essential transcription adaptor/histone $\mathrm{H} 4$ acetyltransferase complex containing Esalp and the ATM-related cofactor Tralp. EMBO J 18: 5108-5119.

Altaf M, Utley RT, Lacoste N, Tan S, Briggs SD, Cote J. 2007. Interplay of chromatin modifiers on a short basic patch of histone $\mathrm{H} 4$ tail defines the boundary of telomeric heterochromatin. Mol Cell 28: 1002-1014.

Altaf M, Auger A, Covic M, Cote J. 2009. Connection between histone $\mathrm{H} 2 \mathrm{~A}$ variants and chromatin remodeling complexes. Biochem Cell Biol 87: 35-50.

Altaf M, Auger A, Monnet-Saksouk J, Brodeur J, Piquet S, Cramet M, Bouchard N, Lacoste N, Utley RT, Gaudreau L, et al. 2010. NuA4-dependent acetylation of nucleosomal histones $\mathrm{H} 4$ and $\mathrm{H} 2 \mathrm{~A}$ directly stimulates incorporation of H2A.Z by the SWR1 complex. I Biol Chem 285: 1596615977.

Avvakumov N, Lalonde ME, Saksouk N, Paquet E, Glass KC, Landry AJ, Doyon Y, Cayrou C, Robitaille GA, Richard DE, et al. 2012. Conserved molecular interactions within the HBO1 acetyltransferase complexes regulate cell proliferation. Mol Cell Biol 32: 689-703.

Balasubramanian R, Pray-Grant MG, Selleck W, Grant PA, Tan S. 2002. Role of the Ada2 and Ada3 transcriptional coactivators in histone acetylation. I Biol Chem 277: 7989-7995.

Berndsen CE, Selleck W, McBryant SJ, Hansen JC, Tan S, Denu JM. 2007. Nucleosome recognition by the Piccolo NuA4 histone acetyltransferase complex. Biochemistry 46: 20912099.

Bian C, Xu C, Ruan J, Lee KK, Burke TL, Tempel W, Barsyte D, Li J, Wu M, Zhou BO, et al. 2011. Sgf29 binds histone $\mathrm{H} 3 \mathrm{~K} 4 \mathrm{me} / 3$ and is required for SAGA complex recruitment and histone $\mathrm{H} 3$ acetylation. EMBO J 30: 2829-2842.

Bock I, Dhayalan A, Kudithipudi S, Brandt O, Rathert P, Jeltsch A. 2011. Detailed specificity analysis of antibodies binding to modified histone tails with peptide arrays. Epigenetics 6: 256263.

Bonasio R, Tu S, Reinberg D. 2010. Molecular signals of epigenetic states. Science 330: 612-616.

Boudreault AA, Cronier D, Selleck W, Lacoste N, Utley RT, Allard S, Savard J, Lane WS, Tan S, Côté J. 2003. Yeast Enhancer of Polycomb defines global Esa1-dependent acetylation of chromatin. Genes Dev 17: 1415-1428.

Cai L, Rothbart SB, Lu R, Xu B, Chen WY, Tripathy A, Rockowitz S, Zheng D, Patel DJ, Allis CD, et al. 2013. An H3K36 methylation-engaging Tudor motif of polycomb-like proteins mediates PRC2 complex targeting. Mol Cell 49: 571-582.

Cao R, Wang H, He J, Erdjument-Bromage H, Tempst P, Zhang Y. 2008. Role of hPHF1 in H3K27 methylation and Hox gene silencing. Mol Cell Biol 28: 1862-1872.

Carrozza MJ, Utley RT, Workman JL, Cote J. 2003. The diverse functions of histone acetyltransferase complexes. Trends Genet 19: 321-329.

Champagne KS, Saksouk N, Pena PV, Johnson K, Ullah M, Yang XJ, Cote J, Kutateladze TG. 2008. The crystal structure of the ING5 PHD finger in complex with an H3K4me3 histone peptide. Proteins 72: 1371-1376.

Chang PY, Hom RA, Musselman CA, Zhu L, Kuo A, Gozani O, Kutateladze TG, Cleary ML. 2010. Binding of the MLL PHD3 finger to histone H3K4me3 is required for MLL-dependent gene transcription. J Mol Biol 400: 137-144.

Chi P, Allis CD, Wang GG. 2010. Covalent histone modifications-miswritten, misinterpreted and mis-erased in human cancers. Nat Rev Cancer 10: 457-469. 
Chittuluru JR, Chaban Y, Monnet-Saksouk J, Carrozza MJ, Sapountzi V, Selleck W, Huang J, Utley RT, Cramet M, Allard S, et al. 2011. Structure and nucleosome interaction of the yeast NuA4 and Piccolo-NuA4 histone acetyltransferase complexes. Nat Struct Mol Biol 18: 1196-1203.

Chruscicki A, MacDonald VE, Young BP, Loewen CJR, Howe LJ. 2010. Critical determinants for chromatin binding by Saccharomyces cerevisiae yng1 exist outside of the plant homeodomain finger. Genetics 185: 469-477.

Ciurciu A, Komonyi O, Boros IM. 2008. Loss of ATAC-specific acetylation of histone $\mathrm{H} 4$ at Lys 12 reduces binding of JIL-1 to chromatin and phosphorylation of histone H3 at Ser10. J Cell Sci 121: 3366-3372.

Conrad T, Cavalli FM, Holz H, Hallacli E, Kind J, Ilik I, Vaquerizas JM, Luscombe NM, Akhtar A. 2012. The MOF chromobarrel domain controls genome-wide H4K16 acetylation and spreading of the MSL complex. Dev Cell 22: 610624.

Couture JF, Skiniotis G. 2013. Assembling a COMPASS. Epigenetics 8: 349-354.

Dawson MA, Kouzarides T. 2012. Cancer epigenetics: from mechanism to therapy. Cell 150: 12-27.

Deng Z, Chen CI, Chamberlin M, Lu F, Blobel GA, Speicher D, Cirillo LA, Zaret KS, Lieberman PM. 2003. The CBP bromodomain and nucleosome targeting are required for Zta-directed nucleosome acetylation and transcription activation. Mol Cell Biol 23: 2633-2644.

Dhar SS, Lee SH, Kan PY, Voigt P, Ma L, Shi X, Reinberg D, Lee MG. 2012. Trans-tail regulation of MLL4-catalyzed H3K4 methylation by H4R3 symmetric dimethylation is mediated by a tandem PHD of MLL4. Genes Dev 26: 2749-2762.

Doyon Y, Selleck W, Lane WS, Tan S, Cote J. 2004. Structural and functional conservation of the NuA4 histone acetyltransferase complex from yeast to humans. Mol Cell Biol 24: 1884-1896.

Doyon Y, Cayrou C, Ullah M, Landry AJ, Cote V, Selleck W, Lane WS, Tan S, Yang XJ, Cote J. 2006. ING tumor suppressor proteins are critical regulators of chromatin acetylation required for genome expression and perpetuation. Mol Cell 21: 51-64.

Dreveny I, Deeves SE, Fulton J, Yue B, Messmer M, Bhattacharya A, Collins HM, Heery DM. 2014. The double PHD finger domain of MOZ/MYST3 induces $\alpha$-helical structure of the histone $\mathrm{H} 3$ tail to facilitate acetylation and methylation sampling and modification. Nucleic Acids Res 42: 822-835.

Du HN, Fingerman IM, Briggs SD. 2008. Histone H3 K36 methylation is mediated by a trans-histone methylation pathway involving an interaction between Set2 and histone H4. Genes Dev 22: 2786-2798.

Egelhofer TA, Minoda A, Klugman S, Lee K, Kolasinska-Zwierz P, Alekseyenko AA, Cheung MS, Day DS, Gadel S, Gorchakov AA, et al. 2011. An assessment of histone-modification antibody quality. Nat Struct Mol Biol 18: 91-93.

Feng W, Yonezawa M, Ye J, Jenuwein T, Grummt I. 2010. PHF8 activates transcription of rRNA genes through $\mathrm{H} 3 \mathrm{~K} 4 \mathrm{me} 3$ binding and H3K9me1/2 demethylation. Nat Struct Mol Biol 17: 445-450.

Filippakopoulos P, Picaud S, Mangos M, Keates T, Lambert JP, Barsyte-Lovejoy D, Felletar I, Volkmer R, Muller S, Pawson $\mathrm{T}$, et al. 2012. Histone recognition and large-scale structural analysis of the human bromodomain family. Cell 149: 214 231.

Fingerman IM, Li HC, Briggs SD. 2007. A charge-based interaction between histone $\mathrm{H} 4$ and Dot 1 is required for H3K79 methylation and telomere silencing: identification of a new trans-histone pathway. Genes Dev 21: 2018-2029.
Fortschegger K, de Graaf P, Outchkourov NS, van Schaik FM, Timmers HT, Shiekhattar R. 2010. PHF8 targets histone methylation and RNA polymerase II to activate transcription. Mol Cell Biol 30: 3286-3298.

Foy RL, Song IY, Chitalia VC, Cohen HT, Saksouk N, Cayrou C, Vaziri C, Cote J, Panchenko MV. 2008. Role of Jade-1 in the histone acetyltransferase (HAT) HBOl complex. J Biol Chem 283: $28817-28826$.

Fuchs SM, Krajewski K, Baker RW, Miller VL, Strahl BD. 2011. Influence of combinatorial histone modifications on antibody and effector protein recognition. Curr Biol 21: 53-58.

Fullgrabe J, Kavanagh E, Joseph B. 2011. Histone onco-modifications. Oncogene 30: 3391-3403.

Grant PA, Duggan L, Cote J, Roberts SM, Brownell JE, Candau R, Ohba R, Owen-Hughes T, Allis CD, Winston F, et al. 1997. Yeast Gcn5 functions in two multisubunit complexes to acetylate nucleosomal histones: characterization of an Ada complex and the SAGA (Spt/Ada) complex. Genes Dev 11: 1640-1650.

Grant PA, Eberharter A, John S, Cook RG, Turner BM, Workman JL. 1999. Expanded lysine acetylation specificity of Gen5 in native complexes. J Biol Chem 274: 5895-5900.

Greer EL, Shi Y. 2012. Histone methylation: a dynamic mark in health, disease and inheritance. Nat Rev Genet 13: 343357.

Gregory GD, Vakoc CR, Rozovskaia T, Zheng X, Patel S, Nakamura T, Canaani E, Blobel GA. 2007. Mammalian ASH1L is a histone methyltransferase that occupies the transcribed region of active genes. Mol Cell Biol 27: 84668479 .

Guelman S, Kozuka K, Mao Y, Pham V, Solloway MJ, Wang J, Wu J, Lill JR, Zha J. 2009. The double-histone-acetyltransferase complex ATAC is essential for mammalian development. Mol Cell Biol 29: 1176-1188.

Han J, Zhou H, Li Z, Xu RM, Zhang Z. 2007. The Rtt109-Vps75 histone acetyltransferase complex acetylates non-nucleosomal histone H3. J Biol Chem 282: 14158-14164.

Hargreaves DC, Crabtree GR. 2011. ATP-dependent chromatin remodeling: genetics, genomics and mechanisms. Cell Res 21: 396-420.

Havasi A, Haegele JA, Gall JM, Blackmon S, Ichimura T, Bonegio RG, Panchenko MV. 2013. Histone acetyl transferase (HAT) HBO1 and JADE1 in epithelial cell regeneration. Am J Pathol 182: $152-162$.

Herz HM, Garruss A, Shilatifard A. 2013. SET for life: biochemical activities and biological functions of SET domaincontaining proteins. Trends Biochem Sci 38: 621-639.

Hiragami-Hamada K, Fischle W. 2014. RNAs-physical and functional modulators of chromatin reader proteins. Biochim Biophys Acta doi: 10.1016/j.bbagrm.2014.03.015.

Horton JR, Upadhyay AK, Qi HH, Zhang X, Shi Y, Cheng X. 2010. Enzymatic and structural insights for substrate specificity of a family of jumonji histone lysine demethylases. Nat Struct Mol Biol 17: 38-43.

Huang J, Tan S. 2013. Piccolo NuA4-catalyzed acetylation of nucleosomal histones: critical roles of an Esa1 Tudor/chromo barrel loop and an Epll enhancer of polycomb A (EPcA) basic region. Mol Cell Biol 33: 159-169.

Huang F, Chandrasekharan MB, Chen YC, Bhaskara S, Hiebert SW, Sun ZW. 2010. The JmjN domain of Jhd2 is important for its protein stability, and the plant homeodomain (PHD) finger mediates its chromatin association independent of H3K4 methylation. J Biol Chem 285: 24548-24561.

Hung T, Binda O, Champagne KS, Kuo AJ, Johnson K, Chang HY, Simon MD, Kutateladze TG, Gozani O. 2009. ING4 mediates crosstalk between histone H3 K4 trimethylation 
and $\mathrm{H} 3$ acetylation to attenuate cellular transformation. Mol Cell 33: 248-256.

Ingvarsdottir K, Krogan NJ, Emre NC, Wyce A, Thompson NJ, Emili A, Hughes TR, Greenblatt JF, Berger SL. 2005. H2B ubiquitin protease Ubp8 and Sgf11 constitute a discrete functional module within the Saccharomyces cerevisiae SAGA complex. Mol Cell Biol 25: 1162-1172.

Ito T, Ikehara T, Nakagawa T, Kraus WL, Muramatsu M. 2000. p300-mediated acetylation facilitates the transfer of histone H2A-H2B dimers from nucleosomes to a histone chaperone. Genes Dev 14: 1899-1907.

Jeong KW, Kim K, Situ AJ, Ulmer TS, An W, Stallcup MR. 2011. Recognition of enhancer element-specific histone methylation by TIP60 in transcriptional activation. Nat Struct Mol Biol 18: 1358-1365.

John S, Howe L, Tafrov ST, Grant PA, Sternglanz R, Workman JL. 2000. The something about silencing protein, Sas3, is the catalytic subunit of NuA3, a yTAF(II)30-containing HAT complex that interacts with the Spt16 subunit of the yeast CP (Cdc68/Pob3)-FACT complex. Genes Dev 14: 1196-1208.

Kueh AJ, Dixon MP, Voss AK, Thomas T. 2011. HBO1 is required for $\mathrm{H} 3 \mathrm{~K} 14$ acetylation and normal transcriptional activity during embryonic development. Mol Cell Biol 31: 845-860.

Kuo MH, Brownell JE, Sobel RE, Ranalli TA, Cook RG, Edmondson DG, Roth SY, Allis CD. 1996. Transcriptionlinked acetylation by Gen5p of histones $\mathrm{H} 3$ and $\mathrm{H} 4$ at specific lysines. Nature 383: 269-272.

Kusch T, Florens L, Macdonald WH, Swanson SK, Glaser RL, Yates JR 3rd, Abmayr SM, Washburn MP, Workman JL. 2004. Acetylation by Tip60 is required for selective histone variant exchange at DNA lesions. Science 306: 2084-2087.

Lacoste N, Utley RT, Hunter JM, Poirier GG, Cote J. 2002. Disruptor of telomeric silencing-1 is a chromatin-specific histone H3 methyltransferase. I Biol Chem 277: 3042130424.

Lalonde M-E, Avvakumov N, Glass KC, Joncas F-H, Saksouk N, Holliday M, Paquet E, Yan K, Tong Q, Klein BJ, et al. 2013. Exchange of associated factors directs a switch in $\mathrm{HBO} 1$ acetyltransferase histone tail specificity. Genes Dev 27: 2009-2024.

Lan F, Collins RE, De Cegli R, Alpatov R, Horton JR, Shi X, Gozani O, Cheng X, Shi Y. 2007. Recognition of unmethylated histone H3 lysine 4 links BHC80 to LSD1-mediated gene repression. Nature 448: 718-722.

Larschan E, Alekseyenko AA, Gortchakov AA, Peng S, Li B, Yang P, Workman JL, Park PJ, Kuroda MI. 2007. MSL complex is attracted to genes marked by H3K36 trimethylation using a sequence-independent mechanism. Mol Cell 28: 121-133.

Laue K, Daujat S, Crump JG, Plaster N, Roehl HH, Kimmel CB, Schneider R, Hammerschmidt M. 2008. The multidomain protein Brpf1 binds histones and is required for Hox gene expression and segmental identity. Development 135: 19351946.

Lee KK, Florens L, Swanson SK, Washburn MP, Workman JL. 2005. The deubiquitylation activity of Ubp8 is dependent upon Sgf1 1 and its association with the SAGA complex. Mol Cell Biol 25: 1173-1182.

Lemak A, Yee A, Wu H, Yap D, Zeng H, Dombrovski L, Houliston S, Aparicio S, Arrowsmith CH. 2013. Solution NMR structure and histone binding of the PHD domain of human MLL5. PLOS ONE 8: e77020.

Lessard J, Wu JI, Ranish JA, Wan M, Winslow MM, Staahl BT, Wu H, Aebersold R, Graef IA, Crabtree GR. 2007. An essential switch in subunit composition of a chromatin remodeling complex during neural development. Neuron 55: 201-215.

Li B, Gogol M, Carey M, Lee D, Seidel C, Workman JL. 2007. Combined action of PHD and chromo domains directs the Rpd3S HDAC to transcribed chromatin. Science 316: 10501054.

Li X, Wu L, Corsa CA, Kunkel S, Dou Y. 2009. Two mammalian MOF complexes regulate transcription activation by distinct mechanisms. Mol Cell 36: 290-301.

Lickert H, Takeuchi JK, Von Both I, Walls JR, McAuliffe F, Adamson SL, Henkelman RM, Wrana JL, Rossant J, Bruneau BG. 2004. Baf60c is essential for function of BAF chromatin remodelling complexes in heart development. Nature 432: 107-112.

Liu L, Qin S, Zhang J, Ji P, Shi Y, Wu J. 2012. Solution structure of an atypical PHD finger in BRPF2 and its interaction with DNA. J Struct Biol 180: 165-173.

Margueron R, Reinberg D. 2011. The Polycomb complex PRC2 and its mark in life. Nature 469: 343-349.

Margueron R, Justin N, Ohno K, Sharpe ML, Son J, Drury WJ 3rd, Voigt P, Martin SR, Taylor WR, De Marco V, et al. 2009. Role of the polycomb protein EED in the propagation of repressive histone marks. Nature 461: 762-767.

Martin DG, Baetz K, Shi X, Walter KL, MacDonald VE, Wlodarski MJ, Gozani O, Hieter P, Howe L. 2006. The Ynglp plant homeodomain finger is a methyl-histone binding module that recognizes lysine 4-methylated histone H3. Mol Cell Biol 26: 7871-7879.

Miotto B, Struhl K. 2010. HBO1 histone acetylase activity is essential for DNA replication licensing and inhibited by Geminin. Mol Cell 37: 57-66.

Mishima Y, Miyagi S, Saraya A, Negishi M, Endoh M, Endo TA, Toyoda T, Shinga J, Katsumoto T, Chiba T, et al. 2011. The Hbol-Brd1/Brpf2 complex is responsible for global acetylation of H3K14 and required for fetal liver erythropoiesis. Blood 118: 2443-2453.

Miyazaki H, Higashimoto K, Yada Y, Endo TA, Sharif J, Komori T, Matsuda M, Koseki Y, Nakayama M, Soejima H, et al. 2013. Ash11 methylates Lys36 of histone H3 independently of transcriptional elongation to counteract polycomb silencing. PLoS Genet 9: e1003897.

Morales V, Straub T, Neumann MF, Mengus G, Akhtar A, Becker PB. 2004. Functional integration of the histone acetyltransferase MOF into the dosage compensation complex. EMBO I 23: 2258-2268.

Musselman CA, Avvakumov N, Watanabe R, Abraham CG, Lalonde ME, Hong Z, Allen C, Roy S, Nunez JK, Nickoloff J, et al. 2012a. Molecular basis for H3K36me3 recognition by the Tudor domain of PHF1. Nat Struct Mol Biol 19: 12661272 .

Musselman CA, Lalonde ME, Cote J, Kutateladze TG. 2012b. Perceiving the epigenetic landscape through histone readers. Nat Struct Mol Biol 19: 1218-1227.

Nagy Z, Riss A, Fujiyama S, Krebs A, Orpinell M, Jansen P, Cohen A, Stunnenberg HG, Kato S, Tora L. 2010. The metazoan ATAC and SAGA coactivator HAT complexes regulate different sets of inducible target genes. Cell Mol Life Sci 67: 611-628.

$\mathrm{Ng} \mathrm{HH}$, Feng Q, Wang H, Erdjument-Bromage H, Tempst $\mathrm{P}$, Zhang Y, Struhl K. 2002. Lysine methylation within the globular domain of histone $\mathrm{H} 3$ by Dot1 is important for telomeric silencing and Sir protein association. Genes Dev 16: $1518-1527$.

Ogryzko VV, Kotani T, Zhang X, Schiltz RL, Howard T, Yang XJ, Howard BH, Qin J, Nakatani Y. 1998. Histone-like TAFs within the PCAF histone acetylase complex. Cell 94: 35-44. 
Patel A, Vought VE, Dharmarajan V, Cosgrove MS. 2011. A novel non-SET domain multi-subunit methyltransferase required for sequential nucleosomal histone H3 methylation by the mixed lineage leukemia protein-1 (MLL1) core complex. J Biol Chem 286: 3359-3369.

Qin S, Jin L, Zhang J, Liu L, Ji P, Wu M, Wu J, Shi Y. 2011. Recognition of unmodified histone $\mathrm{H} 3$ by the first PHD finger of bromodomain-PHD finger protein 2 provides insights into the regulation of histone acetyltransferases $\mathrm{MOZ}$ and MORF. J Biol Chem 286: 36944-36955.

Qiu Y, Liu L, Zhao C, Han C, Li F, Zhang J, Wang Y, Li G, Mei Y, $\mathrm{Wu} \mathrm{M}$, et al. 2012. Combinatorial readout of unmodified H3R2 and acetylated H3K14 by the tandem PHD finger of MOZ reveals a regulatory mechanism for HOXA9 transcription. Genes Dev 26: 1376-1391.

Recht J, Tsubota T, Tanny JC, Diaz RL, Berger JM, Zhang X, Garcia BA, Shabanowitz J, Burlingame AL, Hunt DF, et al. 2006. Histone chaperone Asfl is required for histone H3 lysine 56 acetylation, a modification associated with $\mathrm{S}$ phase in mitosis and meiosis. Proc Natl Acad Sci 103: 6988-6993.

Rodriguez-Paredes M, Esteller M. 2011. Cancer epigenetics reaches mainstream oncology. Nat Med 17: 330-339.

Rokudai S, Aikawa Y, Tagata Y, Tsuchida N, Taya Y, Kitabayashi I. 2009. Monocytic leukemia zinc finger (MOZ) interacts with p53 to induce p21 expression and cell-cycle arrest. J Biol Chem 284: 237-244.

Rokudai S, Laptenko O, Arnal SM, Taya Y, Kitabayashi I, Prives C. 2013. MOZ increases p53 acetylation and premature senescence through its complex formation with PML. Proc Natl Acad Sci 110: 3895-3900.

Saksouk N, Avvakumov N, Cote J. 2008. (de)MYSTification and INGenuity of tumor suppressors. Cell Mol Life Sci 65: 10131018.

Saksouk N, Avvakumov N, Champagne KS, Hung T, Doyon Y, Cayrou C, Paquet E, Ullah M, Landry AJ, Cote V, et al. 2009. HBO1 HAT complexes target chromatin throughout gene coding regions via multiple PHD finger interactions with histone H3 tail. Mol Cell 33: 257-265.

Sapountzi V, Cote J. 2011. MYST-family histone acetyltransferases: beyond chromatin. Cell Mol Life Sci 68: 11471156.

Sarma K, Margueron R, Ivanov A, Pirrotta V, Reinberg D. 2008. Ezh2 requires PHF1 to efficiently catalyze H3 lysine 27 trimethylation in vivo. Mol Cell Biol 28: 2718-2731.

Selleck W, Fortin I, Sermwittayawong D, Cote J, Tan S. 2005 The Saccharomyces cerevisiae Piccolo NuA4 histone acetyltransferase complex requires the Enhancer of Polycomb A domain and chromodomain to acetylate nucleosomes. Mol Cell Biol 25: 5535-5542.

Sendra R, Tse C, Hansen JC. 2000. The yeast histone acetyltransferase A2 complex, but not free Gcn5p, binds stably to nucleosomal arrays. J Biol Chem 275: 24928-24934.

Shen H, Laird PW. 2013. Interplay between the cancer genome and epigenome. Cell 153: 38-55.

Shi X, Hong T, Walter KL, Ewalt M, Michishita E, Hung T, Carney D, Pena P, Lan F, Kaadige MR, et al. 2006. ING2 PHD domain links histone $\mathrm{H} 3$ lysine 4 methylation to active gene repression. Nature 442: 96-99.

Shilatifard A. 2012. The COMPASS family of histone H3K4 methylases: mechanisms of regulation in development and disease pathogenesis. Annu Rev Biochem 81: 65-95.

Smith ER, Cayrou C, Huang R, Lane WS, Cote J, Lucchesi JC. 2005. A human protein complex homologous to the Drosophila MSL complex is responsible for the majority of histone $\mathrm{H} 4$ acetylation at lysine 16. Mol Cell Biol 25: 9175-9188.
Smith E, Lin C, Shilatifard A. 2011. The super elongation complex (SEC) and MLL in development and disease. Genes Dev 25: 661-672.

Smolle M, Workman JL, Venkatesh S. 2013. reSETting chromatin during transcription elongation. Epigenetics 8: 10-15.

Steunou AL, Rossetto D, Côté J. 2014. Regulating chromatin by histone acetylation. In Fundamentals of chromatin (ed. Workman JL, Abmayr SM), pp. 147-212. Springer, New York.

Strahl BD, Grant PA, Briggs SD, Sun ZW, Bone JR, Caldwell JA, Mollah S, Cook RG, Shabanowitz J, Hunt DF, et al. 2002. Set2 is a nucleosomal histone H3-selective methyltransferase that mediates transcriptional repression. Mol Cell Biol 22: 1298-1306.

Suganuma T, Gutierrez JL, Li B, Florens L, Swanson SK, Washburn MP, Abmayr SM, Workman JL. 2008. ATAC is a double histone acetyltransferase complex that stimulates nucleosome sliding. Nat Struct Mol Biol 15: 364-372.

Suka N, Suka Y, Carmen AA, Wu J, Grunstein M. 2001. Highly specific antibodies determine histone acetylation site usage in yeast heterochromatin and euchromatin. Mol Cell 8: 473479.

Sun Y, Jiang X, Xu Y, Ayrapetov MK, Moreau LA, Whetstine JR, Price BD. 2009. Histone H3 methylation links DNA damage detection to activation of the tumour suppressor Tip60. Nat Cell Biol 11: 1376-1382.

Sural TH, Peng S, Li B, Workman JL, Park PJ, Kuroda MI. 2008. The MSL3 chromodomain directs a key targeting step for dosage compensation of the Drosophila melanogaster X chromosome. Nat Struct Mol Biol 15: 1318-1325.

Sykes SM, Mellert HS, Holbert MA, Li K, Marmorstein R, Lane WS, McMahon SB. 2006. Acetylation of the p53 DNAbinding domain regulates apoptosis induction. Mol Cell 24: 841-851.

Tan M, Luo H, Lee S, Jin F, Yang JS, Montellier E, Buchou T, Cheng Z, Rousseaux S, Rajagopal N, et al. 2011. Identification of 67 histone marks and histone lysine crotonylation as a new type of histone modification. Cell 146: 10161028.

Tang Y, Luo J, Zhang W, Gu W. 2006. Tip60-dependent acetylation of p53 modulates the decision between cell-cycle arrest and apoptosis. Mol Cell 24: 827-839.

Tang Y, Zhao W, Chen Y, Zhao Y, Gu W. 2008. Acetylation is indispensable for p53 activation. Cell 133: 612-626.

Taverna SD, Ilin S, Rogers RS, Tanny JC, Lavender H, Li H, Baker L, Boyle J, Blair LP, Chait BT, et al. 2006. Yng1 PHD finger binding to $\mathrm{H} 3$ trimethylated at $\mathrm{K} 4$ promotes $\mathrm{NuA} 3$ HAT activity at $\mathrm{K} 14$ of $\mathrm{H} 3$ and transcription at a subset of targeted ORFs. Mol Cell 24: 785-796.

Tie F, Stratton CA, Kurzhals RL, Harte PJ. 2007. The N terminus of Drosophila ESC binds directly to histone $\mathrm{H} 3$ and is required for $\mathrm{E}(\mathrm{Z})$-dependent trimethylation of $\mathrm{H} 3$ lysine 27. Mol Cell Biol 27: 2014-2026.

Ullah M, Pelletier N, Xiao L, Zhao SP, Wang K, Degerny C, Tahmasebi S, Cayrou C, Doyon Y, Goh SL, et al. 2008. Molecular architecture of quartet MOZ/MORF histone acetyltransferase complexes. Mol Cell Biol 28: 6828-6843.

van Nuland $R$, van Schaik FM, Simonis $M$, van Heesch S, Cuppen E, Boelens R, Timmers HM, van Ingen H. 2013. Nucleosomal DNA binding drives the recognition of H3K36methylated nucleosomes by the PSIP1-PWWP domain. Epigenetics Chromatin 6: 12 .

Vermeulen M, Eberl HC, Matarese F, Marks H, Denissov S, Butter F, Lee KK, Olsen JV, Hyman AA, Stunnenberg HG, et al. 2010. Quantitative interaction proteomics and genomewide profiling of epigenetic histone marks and their readers. Cell 142: 967-980. 
Vezzoli A, Bonadies N, Allen MD, Freund SM, Santiveri CM, Kvinlaug BT, Huntly BJ, Gottgens B, Bycroft M. 2010. Molecular basis of histone $\mathrm{H} 3 \mathrm{~K} 36 \mathrm{me} 3$ recognition by the PWWP domain of Brpf1. Nat Struct Mol Biol 17: 617-619.

Voss AK, Collin C, Dixon MP, Thomas T. 2009. Moz and retinoic acid coordinately regulate $\mathrm{H} 3 \mathrm{~K} 9$ acetylation, Hox gene expression, and segment identity. Dev Cell 17: 674-686.

Wang Z, Song J, Milne TA, Wang GG, Li H, Allis CD, Patel DJ. 2010. Pro isomerization in MLL1 PHD3-bromo cassette connects $\mathrm{H} 3 \mathrm{~K} 4 \mathrm{me}$ readout to CyP33 and HDAC-mediated repression. Cell 141: 1183-1194.

Yun M, Wu J, Workman JL, Li B. 2011. Readers of histone modifications. Cell Res 21: 564-578.

Zentner GE, Henikoff S. 2013. Regulation of nucleosome dynamics by histone modifications. Nat Struct Mol Biol 20: 259-266. 


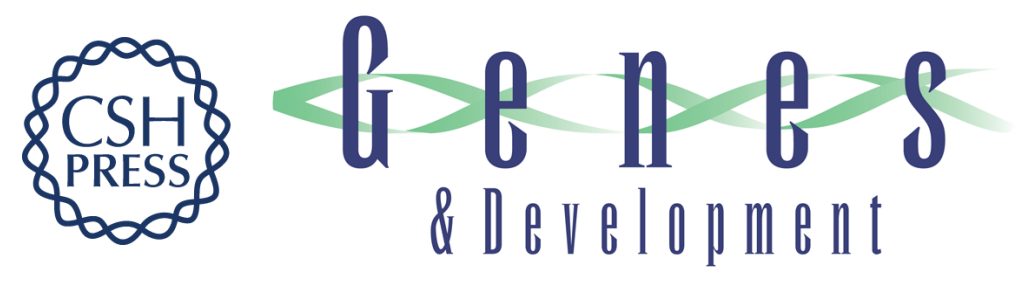

\section{Histone target selection within chromatin: an exemplary case of teamwork}

Marie-Eve Lalonde, Xue Cheng and Jacques Côté

Genes Dev. 2014, 28:

Access the most recent version at doi:10.1101/gad.236331.113

$\begin{aligned} & \text { References } \begin{array}{l}\text { This article cites } 125 \text { articles, 54 of which can be accessed free at: } \\ \text { http://genesdev.cshlp.org/content/28/10/1029.full.html\#ref-list-1 }\end{array} \\ & \begin{aligned} \text { Creative } \\ \text { Commons } \\ \text { License }\end{aligned} \begin{array}{l}\text { This article is distributed exclusively by Cold Spring Harbor Laboratory Press for the first } \\ \text { six months after the full-issue publication date (see } \\ \text { http://genesdev.cshlp.org/site/misc/terms.xhtml). After six months, it is available under a } \\ \text { Creative Commons License (Attribution-NonCommercial } 4.0 \text { International), as described } \\ \text { at http://creativecommons.org/licenses/by-nc/4.0/. }\end{array} \\ & \begin{array}{c}\text { Receive free email alerts when new articles cite this article - sign up in the box at the top } \\ \text { right corner of the article or click here. }\end{array} \\ & \text { Service }\end{aligned}$

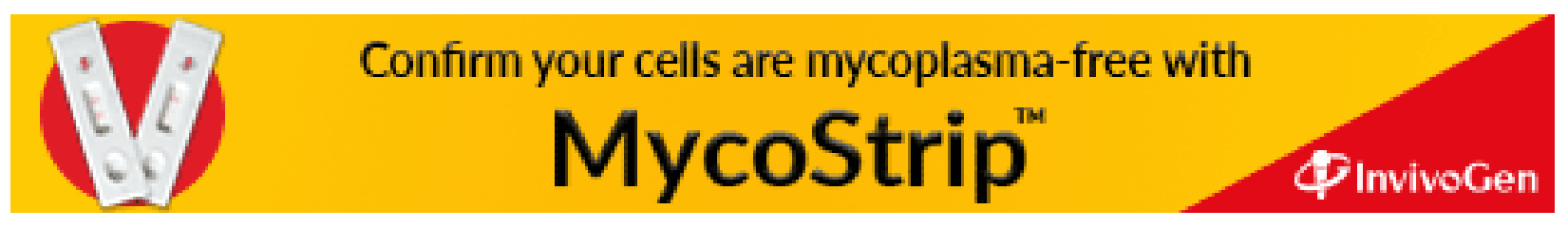

